\title{
HBIM CHALLENGE AMONG THE PARADIGM OF COMPLEXITY, TOOLS AND PRESERVATION: THE BASILICA DI COLLEMAGGIO 8 YEARS AFTER THE EARTHQUAKE (L’AQUILA)
}

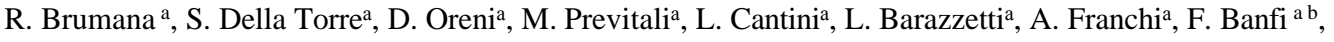 \\ a ABC Department, Politecnico di Milano, Piazza Leonardo da Vinci 32, Milan, Italy \\ (raffaella.brumana, luigi.barazzetti, mattia.previtali, daniela.oreni)@polimi.it \\ dABClabs GIcarus http://www.gicarus.polimi.it \\ (stefano.dellatorre, lorenzo.cantini alberto.franchi)@polimi.it \\ b PhD Internship at the Carleton Immersive Media Studio (CIMS), Carleton Universisty, Ottawa and \\ Autodesk Research Toronto, Canada \\ fabrizio.banfi@polimi.it
}

Commission VI, WG VI/4

KEY WORDS: HBIM, NURBS, PARAMETRIC MODEL, LOD, LOG, LOI, FEA, TOOLS, PRESERVATION

\begin{abstract}
:
In December 2012 ENIservizi (the Italian multi-national energy agency operating in many countries), after the Earthquake that occurred in April 2009, decided to undertake the project 'Re-start from Collemaggio' with the aim of giving new hope to the L'Aquila community, funding around 14 million Euro to restore the Basilica di Collemaggio. The Superintendence Office carried on the restoration project with the scientific support of the Università degli Studi de L'Aquila and the Università La Sapienza di Roma, under the coordination of the Politecnico di Milano. ENIservizi, aware of the BIM potential in the complex building and infrastructure domain in the world, required an advanced HBIM from the laser scanner and photogrammetric surveying to support the diagnostic analysis, the design project, the tender and the restoration itself, today still on course.

Plans and vertical sections were delivered (2012) starting from the surveying campaigns (February and June 2013), together with the first HBIM advancement from the end of 2012 in support of the preliminary-definitive-executive steps of the restoration design project (2013-14-15). Five years later, this paper tries to make a synthesis of the different lessons learnt, in addition to the positive and critical aspects relating HBIM feasibility, sustainability and usefulness to the challenging restoration work.

In particular, the Collemaggio BIM experience anticipated the new Italian Public Procurement Legislation (D.Lgs 50/2016, Nuovo Codice degli Appalti pubblici) aligned with the EUPPD 24/2014: the EU Directive on Public Procurement asked all the 28 EU countries to adopt building informative modelling by February 2016 in order to support the whole LCM (Life Cycle Management), starting from the project and the intervention, through rewarding scores or mandatory regulations. Many analyses foresees to save from around $5 \%$ to $15 \%$ of the overall investment by adopting mature BIM (Level 3 to 5), particularly 4D remotely controlled BIM in support of the LCM, as in the case of maintenance and management process. The tender for Basilica restoration was published in 2015: the process was not developed enough to introduce selective criteria based on BIM adoption by the Construction Industry due to the lack of legislation at that time and the lack of BIM skills among the companies. Nevertheless ENIservizi also separately funded aside the HBIM of the Basilica to tackle an advanced BIM able to address decision-making processes in the heritage domain among the different actors: to support operators, architects, structural engineers, economic computation, construction site management and restoration, the theoretical and practical approach adopted by the HBIM, overcame the current logic based on sequential LoD (from simplex to complex, from the preliminary to the executive design) that is typical of new constructions in favour of a complex LoD approach that could guarantee management of the richness, unicity and multiplicity of each component and the maximum degree of knowledge in order to derive the decisions from the starting phases of the project. On the lesson learnt from this experience, the process of updating the current codification criteria (UNI11337-2009) was started with a draft proposal stimulating a debate for the future of HBIM adoption.
\end{abstract}

\section{INTRODUCTION}

On April 6th, 2009 at 3:32 a.m. an Earthquake (Richter Magnitude 5.9) struck L’Aquila (Central Italy): 309 victims, 65000 displaced people. More than 10 billion euro of estimated damage, about 100 churches unusable and uninhabitable for the major collapses, along with thousands of historic buildings in the old town centres. Among them, the Basilica di Collemaggio was significantly stricken: the dome, the transept with the central vaults and triumphal arches collapsed, and great damage occurred to the pillars, to the apses, and to the longitudinal north front with the 'Holy Door'.

The Basilica, a world-famous medieval church that attracts about 30,000 people for the yearly Feast Day, is a Romanesque masterpiece characterized by a dense, fascinating history and construction phases, that began in 1270: every year on 28-29th August the Forgiveness Feast Day (Festa della Perdonanza) is celebrated, with the procession ceremony transferring the original Bull from the Municipality to the Holy Door of the Basilica. The result is an extraordinary, unique mix of tangible and intangible values to be preserved and transferred to the future.

The challenge was to improve shaping BIM tools (Volk, 2013) tuning BIM for existing buildings toward Built Heritage Conservation (Della Torre, 2015) to obtain a BIM able to combine all the complexity of the geometrical shape (Barazzetti, 
2015) with the historical and archive research and with construction technology analysis, in order to support the design project, preservation and decision-making, the management of critical issues regarding the need to preserve material authenticity and construction techniques, and the need to guarantee safety in case of other earthquakes with worse energy dissipation (Figure 1). Given the main aim, which was to preserve the maximum level of material authenticity, functional behaviour and construction techniques, BIM generation of the Basilica needed to take into account the complex morphology of the different ancient structures and the different transformations made with the support of the historical research carried out by the Università La Sapienza, as a result of the different construction phases plus the earthquake effects.

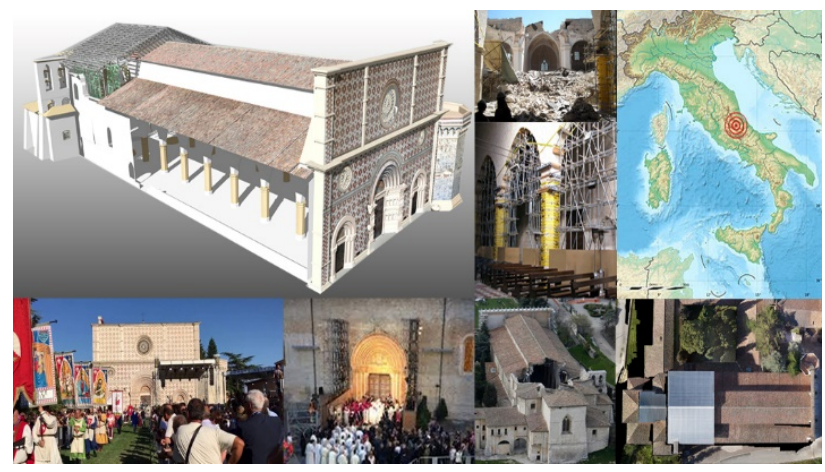

Figure 1. Earthquake damages, the Holy Door during the Jubilee Forgiveness procession, and 3D textured models

Starting from surveying (Barazzetti, 2016), the HBIM model was conceived to be updated and adapted to the different BIM users in order to support different project purposes (2013-14): a. the diagnostic analysis, with the analysis of material and decay, and the overall restoration project; b. the simulation scenario of different solutions for making decisions about the crashed dome; c. construction site project management, including simulation of the scaffoldings in order to keep the Basilica partially usable during the different phases of restoration; d. the structural analysis by the structural engineers supported by a fully interoperable BIM to FEA process; e. the Work Breakdown Structure (WBS) of the activities and the computational phase, enriching the analysis contribution (surface decay analysis and preservation project).

\section{H-BIM, MANAGING THE PARADIGM OF COMPLEXITY: SCANS TO GENERATIVE NURBS MODELLING}

The main peculiarity of BIM applications is the capacity to link various types of data and information to the 3D Objects, favouring the dissemination of the intangible values of built heritage during the life cycle (LCM) of the building.

In the following picture, the generative process from the first phase of processing is represented by the creation of accurate 3D parametric objects (Figure 2).

The seismic actions caused damage to the walls, pillars, and vaulted elements of the basilica. They were affected by several local effects, changes of plane, vertical settlements, rotation, structural cracks and out of plumbs $(10 \div 30$ centimetres).

To this aim, the HBIM model was generated from laser scans and integrated by 3D multispectral photogrammetric image processing (in situ and UAV-based): this made it possible to continue the 1st assessment, in addition to supporting the diagnostic, material and decay analysis, the structural evaluation, and the design process.

Under the technological aspect, parametric BIM models are generally managed for new construction processes following a simple to complex logic in model detailing. Even the latest developments of parametric applications, unfortunately, do not provide advanced tools, being time-consuming for model generation.

Methods capable of processing Non-Uniform Rational BasisSplines (NURBS) to manage complex parametric BIM (Scans to NURBS) with multiple levels of details (Mixed and Reverse LoDs) based on accurate 3D surveys have been experimented with promising results (Banfi, 2016).

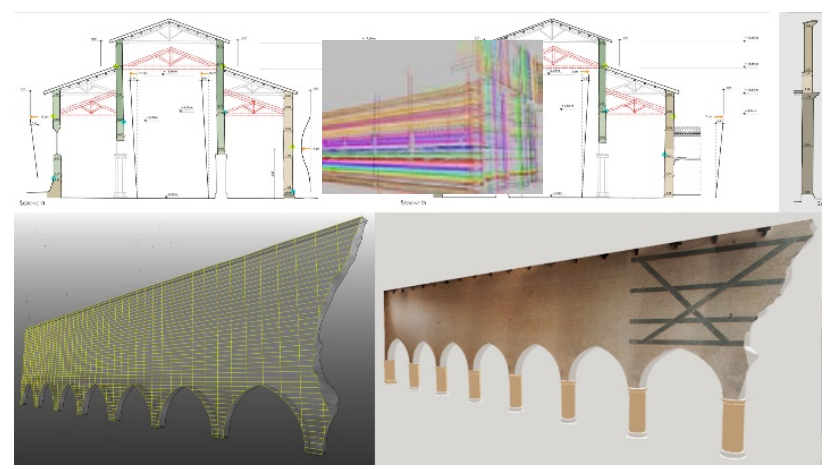

Figure 2. From multi-sliced wireframe to the NURBS-based complex modeling followed for each 3D parametric object

The HBIM of the Basilica was conceived as an interoperable tool able to manage different steps of the restoration (diagnostic analysis, finite element analysis, LCA/LCM, economic analysis, construction site) and to store a great quantity of information to support economic analysis and activity planning (WBS). Numerous challenging decisions to guarantee the maximum degree of preservation of material authenticity and construction techniques have been faced, many of which are still on course. The HBIM challenge is to enhance instruments and tools able to take into account the dynamic characteristic of the masonry structure, the fragility of the elements and of the overall system asking for a new equilibrium after the earthquake: as in the case of the nave system with the arches and damaged pillars, the cracked apse, the longitudinal front with Holy Door characterized by relevant out of plumbs, the wooden trusses and roof, here used as a connection system to be reinforced with new steel elements and tie rods maintaining the elastic behaviour, avoiding past mistakes of the restored dome totally crashed, differently from the arched walls, safe after the earthquake. This is the case of the BIM of the ancient pillars and the ashlar-based-LOD built to support preservation of the maximum number of pillars and of the single stones: their restoration is on course, many have been saved, maintaining the undamaged ashlars as much as possible, and substituting the damaged and crashed ones.

Based on the assumption that historical buildings are made of specific structural elements such as irregular walls, vaults, arches, and not all of them are properly represented by threedimensional objects in clustered BIM databases, the following study describes a generative process capable of creating specific and accurate three-dimensional historic elements of a medieval basilica damaged by earthquake.

The main goal of the Historic Building Information Modelling (HBIM) of the Basilica was the improvement of the level of transmissibility of a large quantity of data between different experts such as architects, designer, restores, structural engineers 
involved in the 3D survey, structural analysis, design and restoration phases of the basilica.

The transmission of the high level of information depends on a proper generation of new, specific and complex objects, both in terms of modelling (morphological aspects) and management of linked data (typological aspect).

The mutual transmission of information during the conservation and structural restoration of architectural heritage required high levels of interoperability of exchange formats, and the combination of various Advanced Modelling Techniques (AMT) in order to get an accurate three-dimensional parametric model. AMT has solicited research tests with particular emphases on 'knowledge' of 3D modeling innovative logics and the development of digital tools. The need of the restoration projects was to improve the generative process for complex elements with a high level of parametrization (3D Objects/Editable information), starting from the scanned shapes, and providing a scientific basis to make engineering decisions. The generation of smart complex 3D objects has increased the management of big data such as 3D survey scans, historical documentation and decay, and computing analysis.

The following paragraph describes a novel HBIM generation method applied to the Basilica. The flexibility and scalability of a novel generative method of H-BIM for the Basilica of Collemaggio have made it possible, through vigorous 3D modeling tests and evaluations, to improve the level of accuracy (LoA) and information (LoI) of each architectural and structural element of the damaged church.

The method applied to the generative process of the H-BIM provided the integration of Non-Uniform Rational Basis-Spline (NURBS) modelling (Piegl,1997) with the parametric logic of the BIM application. The NURBS model of the basilica is a mathematical representation able to achieve complex threedimensional architectural and structural objects, transmitting the accuracy level of the data sources (point - clouds) collected by laser scanning and photogrammetry. In recent years, drawing the profiles in 3D was mandatory for defining the wire frame models. The models were defined from their physical edges (Figure 3).

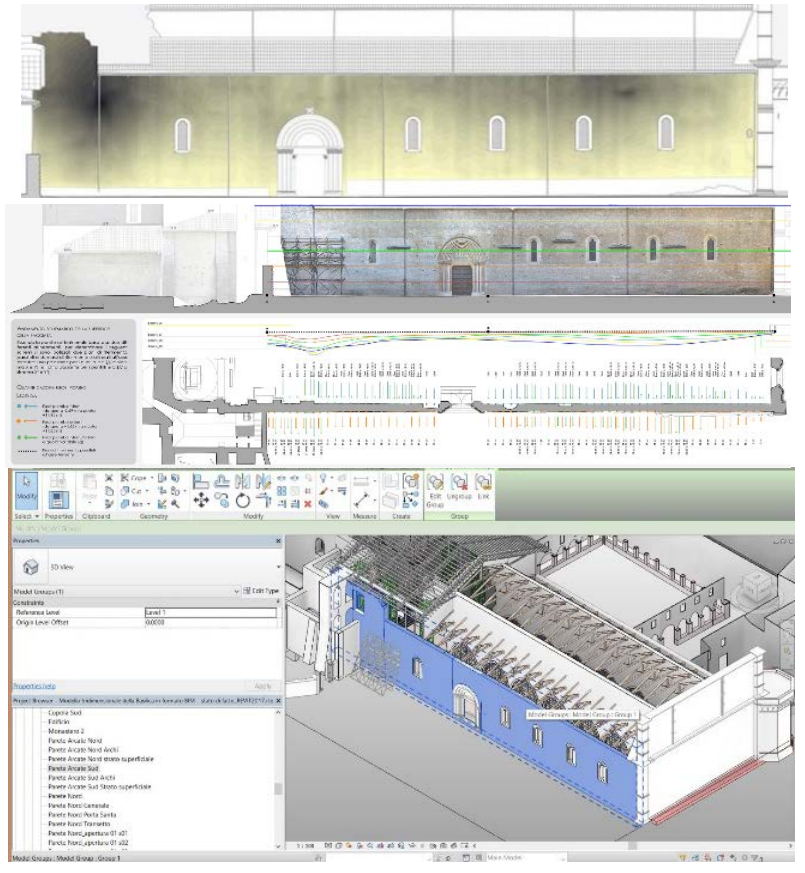

Figure 3. The example of the NURBS-based BIM modelling of the damaged north front with the Holy Door
The study carried out on NURBS and geometric primitives led to improvements in the level of automation and accuracy of each element. Thanks to the combination of various advanced modelling techniques, and the proper use of generative profiles, the level of automation fell from semi-automatic to automatic, avoiding long lead times and the relatively high costs involved in the digital 2D/3D representation. The generation of proper geometric primitives and the management of the generative digital process led to the creation of transmissible threedimensional elements. Clustering exchange formats (.dgw,.sat.,.stp,.pts) made it possible to obtain and transfer 3D slices, profiles, control edges and complex shapes from a versatile 3D NURBS modeller (MC Neel Rhinoceros) to the most used comprehensive BIM application (Autodesk Revit).

\subsection{H-BIM: from a NURBS-based model to 3D graphic integration and management of the diagnostic phase, with the analysis of materials and decays}

The main peculiarity of BIM applications is their capacity to link various type of data and information to the 3D Objects, favouring dissemination of the intangible values of built heritage during the life cycle (LC) of the building. The seismic actions caused damage to the supporting walls of the basilica, which were affected by several local effects, changes of plane, vertical settlements, rotation, structural cracks and out of plumbs.

The restoration project required a system capable of linking and converting traditional CAD drawings into BIM objects, in addition to the generation of a parametric model.

The following picture depicts the generative process from the first phase of processing, through the modelling phase, to the creation of accurate 3D parametric objects. (Figure 4). The main reason for generating $3 \mathrm{D}$ BIM mapping of materials was that 2D drawings do not show real permanent deformations, specific structural deterioration, suffered damage and accurate quantification in one overall visualisation.

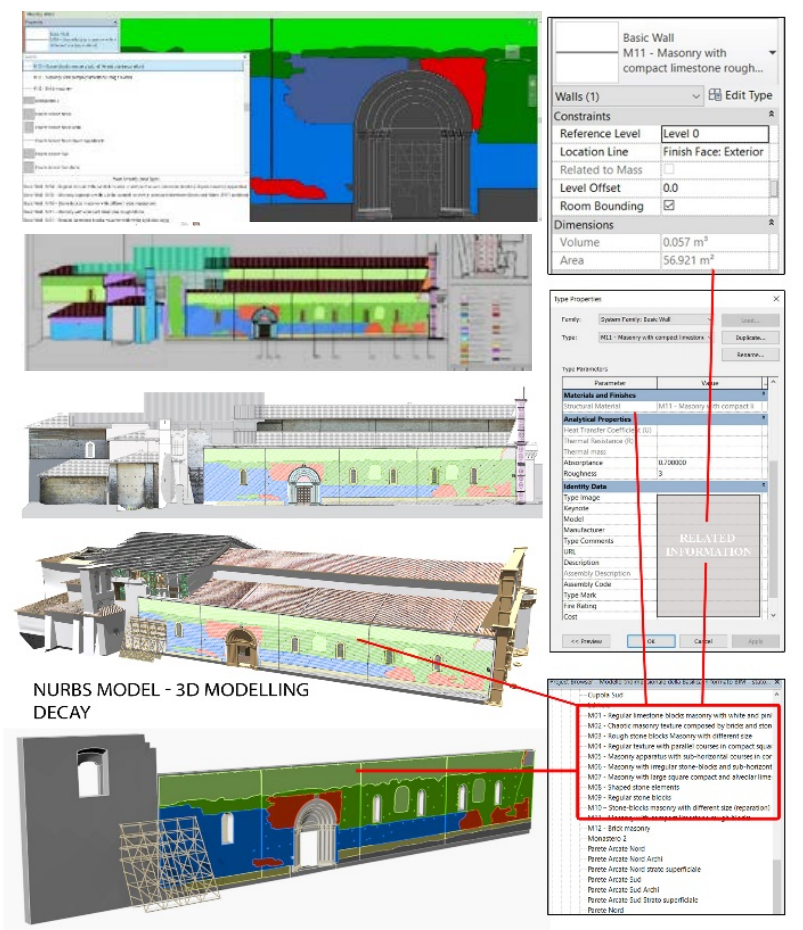

Figure 4. From CAD mapping drawings of Materials and Decay to 3D BIM management. The decay analysis is incorporated into the NURBS-based model 
The main reason for generating 3D BIM mapping of materials was that 2D drawings do not show real permanent deformations, specific structural deterioration, suffered damage and accurate quantification in one overall visualisation. The information collected during the life cycle of buildings will be linked to the inherent values of a specific element. Thus, each element was included in a digital system that allowed a holistic approach for various disciplines, favouring data sharing among the different experts. The following procedure shows the generation of a specific structural element and the inclusion of information such as material, stratigraphic information, decay and structural failure of the north wall of the Basilica. The method is based on the integration of the thematic mappings drawings in the HBIM, and generation of $3 \mathrm{D}$ objects corresponding to various decay areas identified by the above analysis

Generative requirements:

- Automatic maps recognition from CAD to Autodesk Revit (C)

- Check the warnings in the BIM application

- To select the geometric boundaries of each decay area. they must be properly create in traditional 2D CAD drawing application for the automatic recognition

- To orient the geometric primitives in MC Nell Rhinoceros (C) and define the exchange formats from .3dm to .dwg.

- Realise the wireframe of each 3D mapping profile with the internal automation in Autodesk.

The creation of specific objects made it possible to go beyond the simple correlation between drawing, 3D model and data. Each 3D element was associated with the following list of information: identification number, stratigraphic information on the wall such as materials, thickness, length, area, volume, resistance, thermal mass, type of decay, the reason for decay. The historic database has been created in order to improve the BIM interoperability toward the different actors (i.e. cost estimations). All these types of information allowed a high level of sharing during the process of the restoration project of the Basilica for each parametric object and after the restoration updating the as-built (Figure 5).

\section{HBIM MANAGEMENT OF THE STONE COLUMNS OF THE NAVE: FROM THEIR SURVEY TO THEIR CONSERVATION}

\subsection{Geometrical survey of stone ashlars and HBIM}

During the diagnostic investigation (2013-14), the exact geometry of the columns of the nave was derived, while it was not always possible to analyse the inner core of the pillars. Similarly, laser scanner and photogrammetric data could not be used to identify ashlar division, because of the dense network of wooden boards on four of the eight faces of the pillars, and because of the provisional horizontal fabric hooping. It was therefore essential to proceed with a hands-on survey of each pillar, in order to draw the shape and disposition of every stone element (Figure 6). The geometrical and material analysis conducted on the pillars showed a generalized diffusion of patch elements, characterized only by a hypothesized thickness, presumably variable from one zone to another. The crack pattern and position of the broken or degraded ashlars were mapped in detail, in order to plan the different conservation activities: replacement, integration or consolidation. It was evident that the number of elements to be completely substituted would be added or changed on the restoration site); it would also be especially necessary to deeply investigate all the areas interested by past restoration interventions, where the cracks were covered using filling mortars made from the powder of the same stone, hiding any other broken ashlar.The geometrical and material analysis conducted on the pillars, showed a generalized diffusion of patch elements, characterized only by a hypothesized thickness, presumably variable from one zone to another. The crack pattern and position of the broken ordegraded ashlars were mapped in detail, in order to plan the different conservation activities: replacement, integration or consolidation.

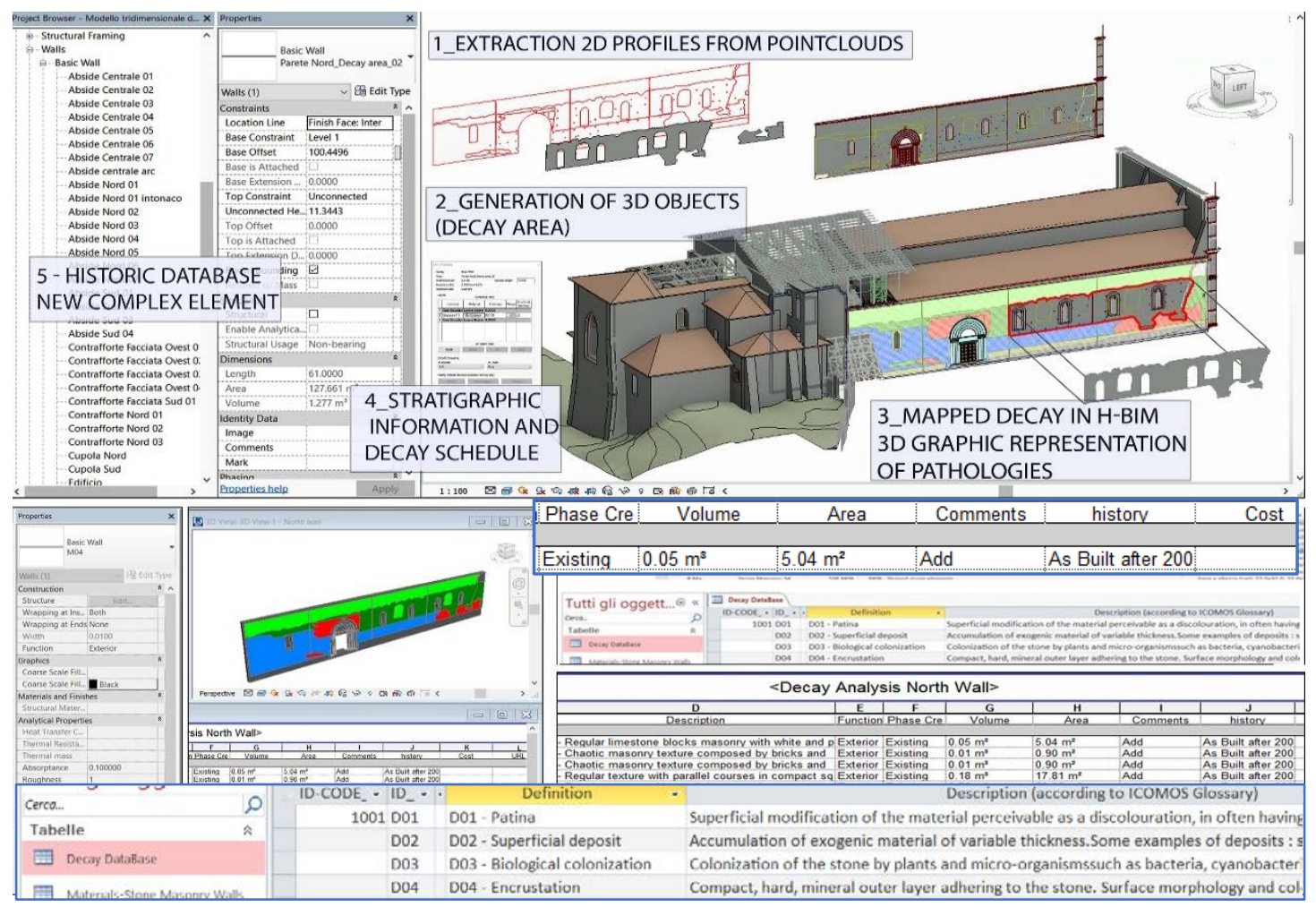

Figure 5. HBIM Material and Decay Mapping DB data management. From 2D to 3D HBIM NURBS model. Each material area is a parametric Object in the BIM DB with the 3D shape of the Objects (i.e. walls, vaults) belonging to the different Families 
It was evident that the number of elements to be completely substituted would be added or changed on the restoration site); it would also be especially necessary to deeply investigate all the areas interested by past restoration interventions, where the cracks were covered using filling mortars made from the powder of the same stone, hiding any other broken ashlar.

Similarly, only constructive suppositions could be made about the size of the mortar internal core of the pillars (visible only in column n. 6), definitely variable in position and dimension (Figure7). The geometric survey recognition of the ashlars of every pillar was finally drawn in 2D (plan and fronts), and in 3D using BIM technology (Oreni, 2017).

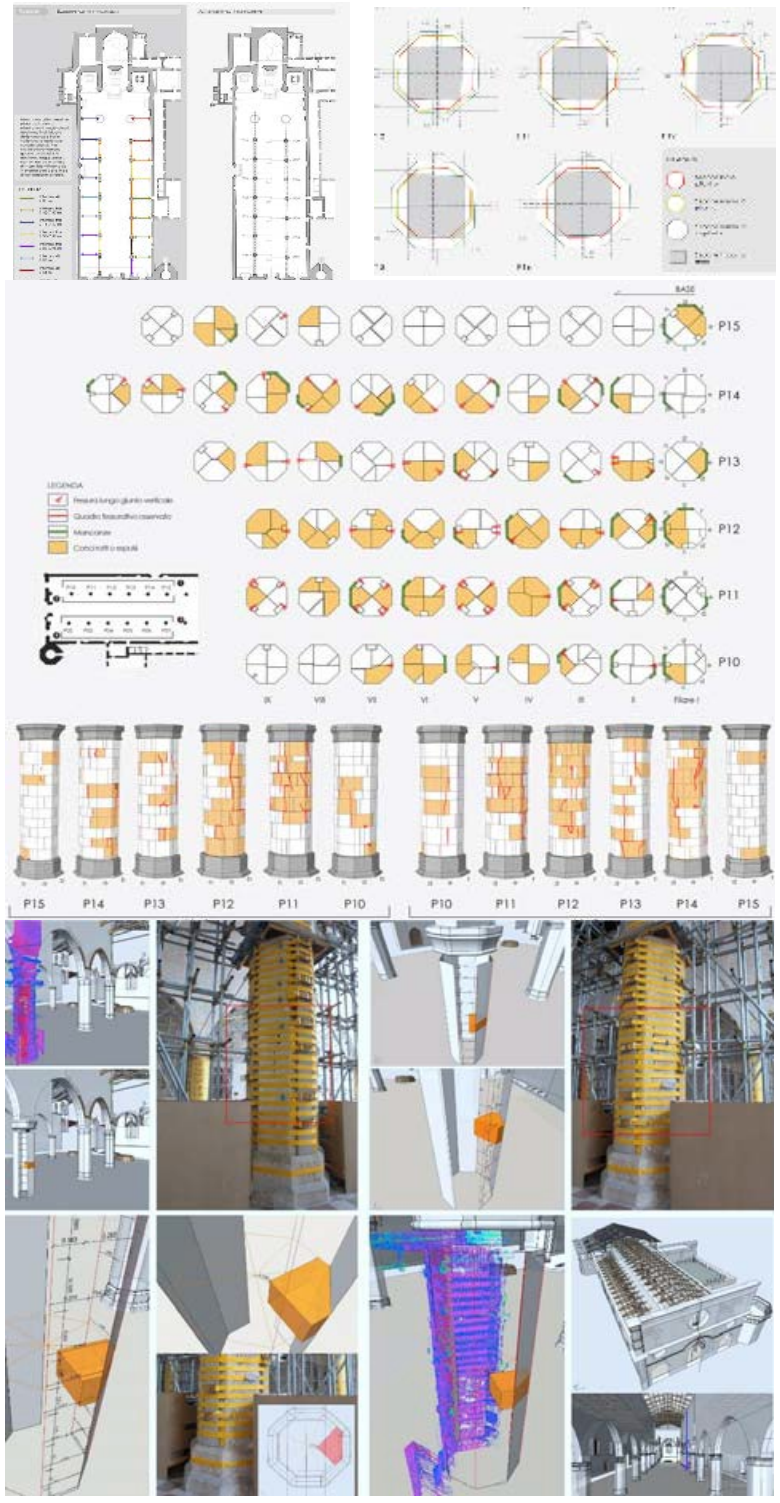

Figure 6. From the scan profiles to the 3D models of the left nave's columns and their stone ashlars. In yellow, the broken ashlars (diagnostic analysis)

Once column restoration had been started (2016), it was possible to gradually compare the geometric information ascertained or drawn from diagnostic investigation with the information procured from the restoration activities, especially concerning the central pillars, completely disassembled, as expected from the project.

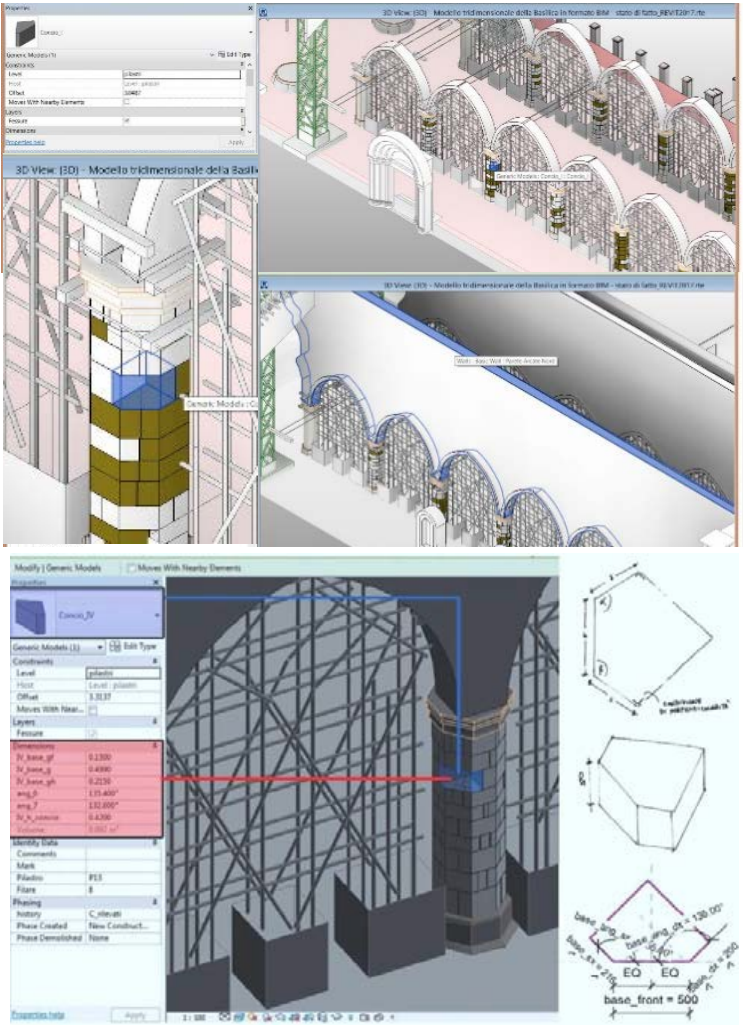

Figure 7. HBIM model of the arches and the octagonal stone pillars (above). Pillar n. 6 of the nave (bottom): on the right the hands-on survey of the only completely visible ashlar element.

\subsection{Comparison between the geometrical data on columns and the information derived from the restoration activities}

The first phase of column restoration consisted in the removal of the vertical loads, by progressively inserting temporary metal structures under the two relevant arches (Figure 8).. This operation made it possible to continue with the on-site intervention of stone ashlar replacement or with the complete disassembly of the columns.

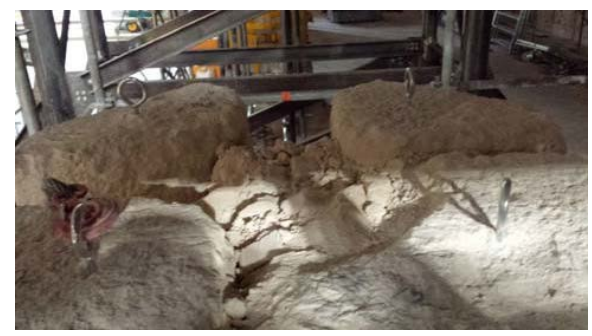

Figure 8. Top images of a pillar during disassembly; in the centre, the irregular mortar core of the column

First, starting from the upper part, the ashlars of the central pillars (P04-05-06-12-13-14), the most stressed by the seismic actions and extremely degraded (Crespi, 2016), were disassembled, numbered and reassembled on the floor. This operation made it possible to verify the exact geometry of the stone elements, to evaluate the material and thickness of the central core (Figure 8), to recognize the broken elements (not visible from the outside) and to refine and rectify the drawings made during the diagnostic phase (Figure 9). 

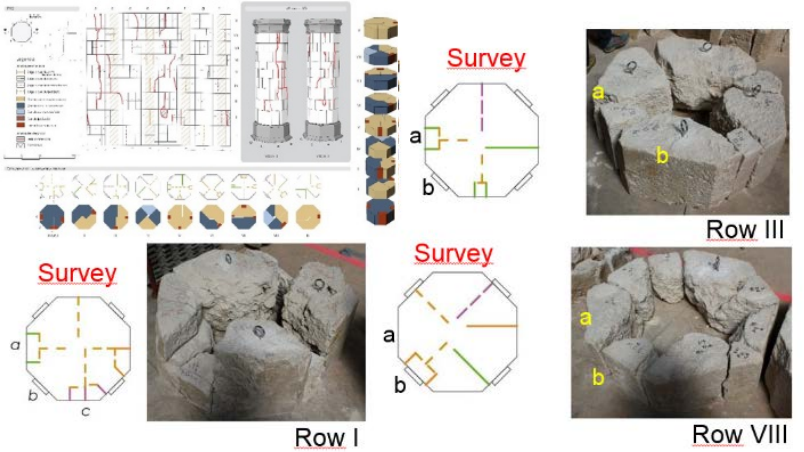

Figure 9. Pillar n. 12. The drawings made during diagnostic phase without inspections. State of the art of the ashlars before and after disassembly: rows I, III, VIII, the external deterioration of the stone in good condition in the inner part

Comparing all the information gathered made it possible to validate the survey method used in the diagnostic phase and the results obtained, both in terms of geometric analysis and of the volume stone to be replaced (approximately $50 \%$ of the total volume of the columns). All in all, in fact, a good correspondence was registered between the geometry of the detected blocks and the real ones, albeit with some expected, and in some cases also important, differences. The major differences are linked to the failed detection of the broken stone elements in the inner part, along with fracture lines not visible from the outside, or covered by temporary wooden structures. As assumed in the diagnostic phase, the substantially limited thickness of the patch stone elements, mostly due to restoration work performed by the Superintendent Moretti in the 1970s, was recorded. In fact, the restoration phase gave back a multiplicity of thicknesses. In the case of Pillar n. 12 the disassembly of the central columns of the nave has shown a big difference between the shapes of the core of each row, depending on the stone ashlar dimension and disposition (Figure 10).

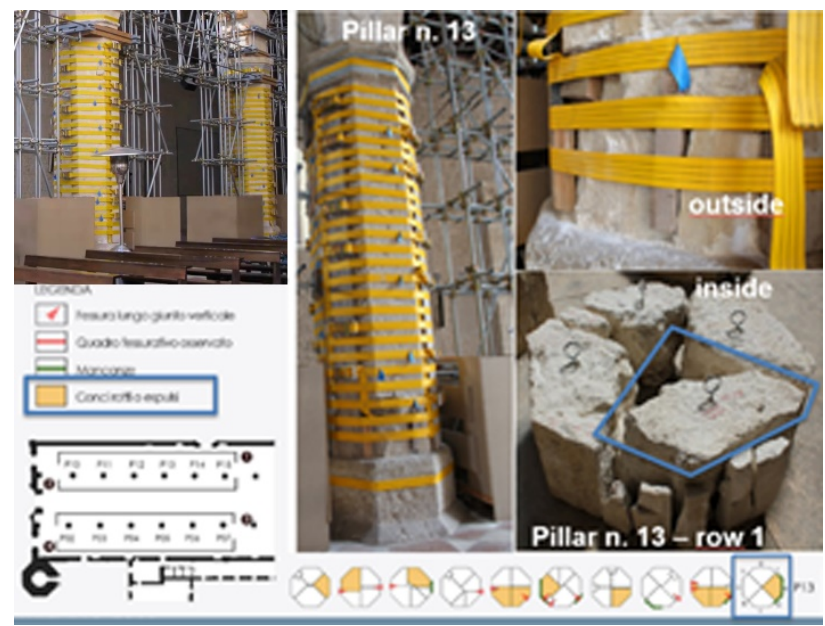

Figure 10. Pillar n. 13. A case of better ashlar stone conservation with respect to the hypothesized state of the art of the inner before disassembly and after reassembly.

The external deterioration of the stone, in good condition in the inner part, is evident.

In some rows, the central core occupies up to $50 \%$ of the total area, compromising the mechanical characteristics of all the elements. The material filling the core is the so-called "incoherent mortar", poor in aggregates, similar to the mortar analysed in pillar n. 6 during the diagnostic phase. Throughout the restoration activities, it was possible to recover some stone elements, in some cases using metal connections or paste, which was considered seriously damaged in the diagnostic step; in that case, their external condition did not reflect the inner one. Therefore it was possible to recover them (Figure 11).
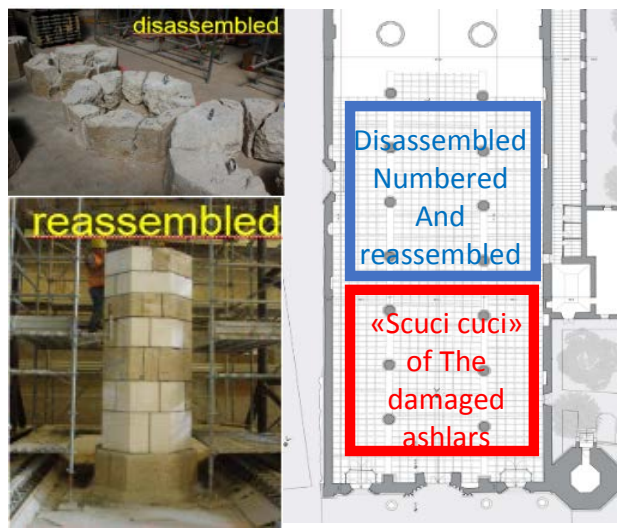

Figure 11. The two different conservation activities planned on the pillars in the design project: global disassembly \& reassembly of the stone ashlars with approximately $50 \%$ of the stone volume saved and $50 \%$ replaced (red); «scuci cuci» proposal with punctual replacement of the single damaged stone ashlars (blue)

\section{MANAGING COMPLEXITY CHALLENGE: MODELING, CODIFICATION, OPEN ISSUES}

Given the achieved HBIM generation managing morphologic complexity and unicity, many difficulties remain in using BIM for conservation projects, linked both to the complication in modelling irregular geometric elements, and to their adoption by administrators and construction enterprises - who have to work in a new 3D environment from the traditional 2D - which lead the research toward 2 main directions:

$>$ Scan to BIM: filling gaps in time-cost effectiveness

- increasing technical skills lowering time-consuming modelling costs;

- BIM modelling protocols and specifications to facilitate the process of preserving unicity and multiplicity;

$>$ the challenge of HBIM-Modelling unicity by BIM Obj INSTANCE in support of the overall behaviour and preservation decision making;

boosting interoperability among actors in the preservation plan and on-site preservation practices;

specification and codification criteria linking HBIM generation from the preservation practices to all LCM; further investigation of structural analysis taking into account the overall BIM modelled to derive preservation guidelines.

\subsection{Toward Restoration Codification Criteria: UNI 11337- 2017 (Draft). LoD/LoG/LoI to manage unicity}

Starting from different current codifications in an international framework (i.e. AIA, AEC) progressively focusing on the HBIM specificity (Fai, 2013, 2014; Brumana, 2013) and from the lesson learnt from the Collemaggio HBIM, a drafted proposal was delivered in substitution of the UNI 11337-2009 Codification Criteria for Construction Products and Processes, defining a specific Level of Geometry (LoG) and the Level of Information 
(LoI) in the 'Restoration' process domain (UNI 11337-3-2017 draft). The new codification defines LoDs A-E in the restoration project representation as inconsequential, with the exception of simplified specialist models: in facts, it introduces new LoDs ' $\mathrm{F}$ G' requiring a detailed geometric description of all the components (LoGs F-G), taking into account their unicity, the state of the art documenting materials and decay, together with intervention updating. Also, it defines a related coherent Level of Information (LoI F-G) to be updated during the LCM and maintenance process. 'As built' updating is required as a fundamental part of the chain from the state of the art analysis to the 'longue durée' following the different interventions on the object across the LCM (Figure 12).

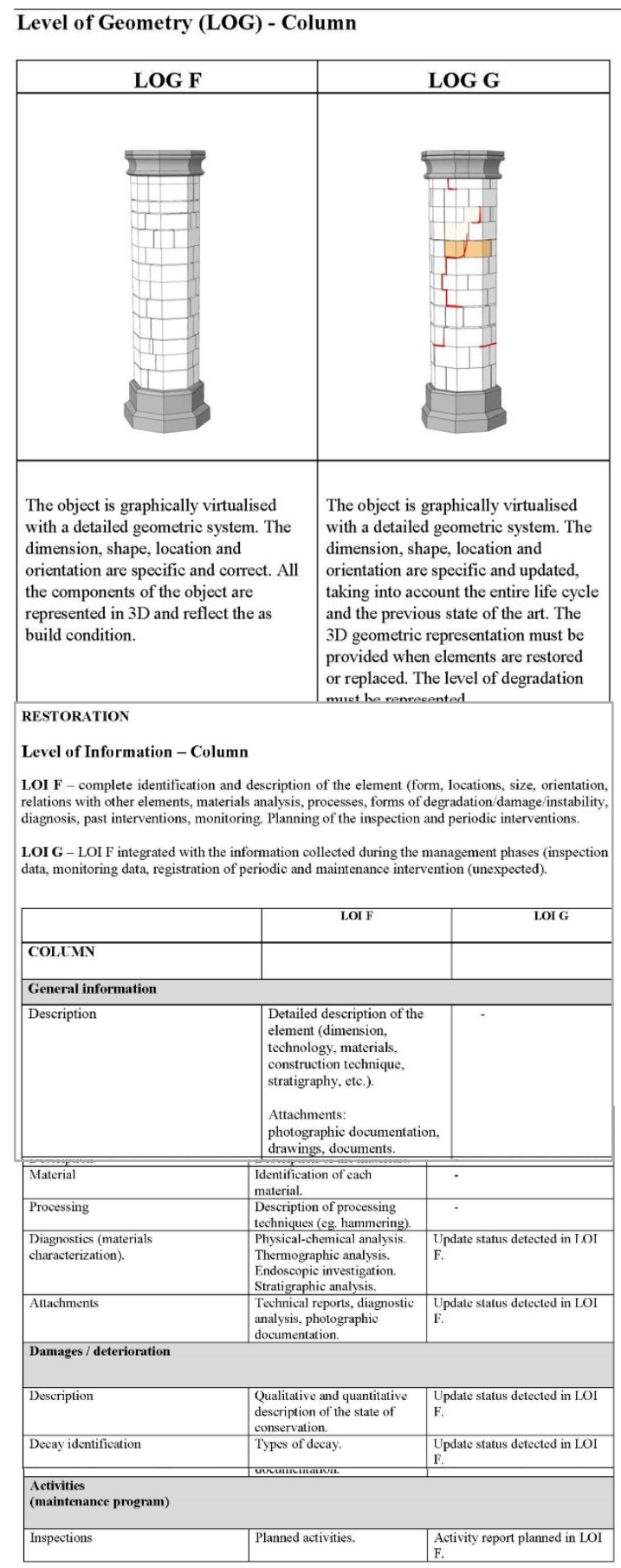

Figure 12. UNI 11337-3-2017 draft of the proposed LoG-LoI ('F and G')
4.2 HBIM challenging issues linking structural analysis to the complexity: what's further to be investigated

A few open questions: did we manage the paradigm of HBIMs complexity linked to preservation challenges? In other words, can we boost the level of preservation challenging aspects tackling BIM tools and interoperability? How to reach it at a time-cost effectiveness favouring the adoption by the public and private subjects? Which lacks and gaps have to be overcome in the future, besides the BIM modelling issues?

After obtaining the HBIM of each INSTANCE as described, the overall sum of elements was tested to support a full interoperable HBIM for many purposes: a. the design project simulation; $b$. the Construction SIte data Management (COSIM); c. the structural analysis: the HBIM was converted from the parametric BIM platform, with the possibility of managing the Finite Element Analysis (BIM to FEA) using specific exchange formats and new modelling tools to support the structural choices. An overall model of the basilica managed by MIDAS $\odot$ was obtained (Barazzetti, 2015), entailing all the morphological complexity of each element without any simplification (Figure 13).

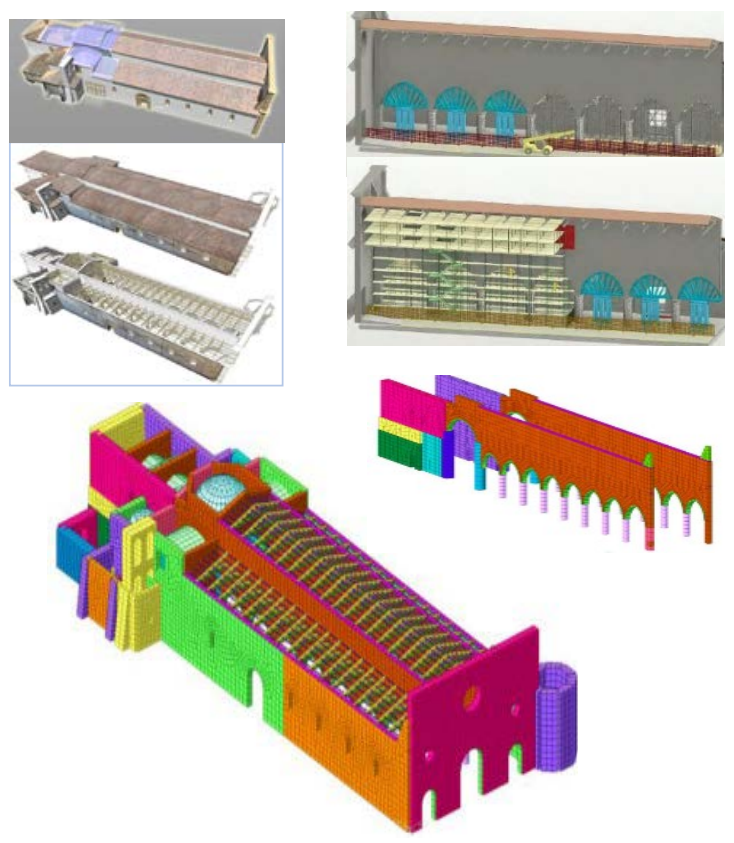

Figure 13. HBIM interoperability. The HBIM of the Basilica is fully interoperable with design project simulation, construction site management (COSIM) and structural analysis (BIM to FEA Revit (C) Midas (C)

After this experience still, on course, we could say that the most HBIM challenging issue is represented by the structural analysis. In theory, this result certainly represents an important step in the process linking HBIM complexity to the structural analysis domain. In the case of single elements data management (i.e. the case of the Pillars preservation), we could say that HBIM heavily contributed to support the preservation challenge, given that the demolition and reconstruction of all the pillars was one of the starting option and also one of the main arguing among specialists, restorers and structural engineers, between regulations on seismic risk reduction, the safety framework, and preservation ones. On the other side a contribution of the HBIM model to the whole dynamic behaviour, and its simulation to enhance the preservation, is still lacking under different points of view. As for the BIM/FEA results, we can't say that it was achieved a tangible difference with respect to the traditional 
simplified modelling used by the structural analysis to derive the structural behaviour: it was used to plan structural interventions. From the restoration project to the on-site intervention, many difficult compromises were made with different sensibilities and disciplinary backgrounds, at times saving precious historical witnesses, as in the case of the historical pillars here described, at other times making difficult choices to partially sacrifice functional authenticity under the structural point of view: this requires to boost the research toward simulation and HBIM complexity management in order to enhance the level of preservation, for example, better understanding elastic and dynamic relationships, and re-action capacities among the different elements (pillars, arches, walls, vaults, domes, trusses facades, and wooden roof), taking into account their construction technologies, in order to adopt the softer measures of connecting them. It could, for example, be worth analysing more extensively the mixed stone-masonry walls to understand their overall behaviour (the arched nave walls and the perimeter ones like the north wall) before and after the removal by Moretti in the Seventies of the baroque vaulted system: that vaults reinforced the lean vertical structure helping in past earthquakes to preserve the structure of the naves: it could be useful for avoiding the mistakes of the past, such as the intervention of Moretti on the central dome, which totally collapsed in 2009.

\section{CONCLUSION}

The NURBS-based modelling adopted for the HBIM of the Basilica allows generating interoperable parametric objects that can be associated with different properties and information, as historical information and external DBs, to external programmes as well (i.e. BIM to FEA, WBS), and user community. The HBIM of the Basilica di Collemaggio can now be conceived as a gateway to be constantly enriched with semantic vocabularies - as in the case of materials and decay or historical data -, thinking of it as an innovative hub to access the digital tangible heritage artefacts, whose conservation represents the vehicle for transmitting intangible values among citizen community. Managing the paradigm of complexity by the specificity of each object instance allows to enhance the knowledge from where to derive and boost the conservation level, as shown in the case of the pillars. The possibility of having an accurate survey of the damaged structures and a detailed HBIM model was a great opportunity, not only in terms of knowledge enrichment, but also in terms of production of a project that could be as close as possible to the real condition of the building, developing ad hoc solutions. Getting a rich HBIM model starting from accurate surveys is an unavoidable starting point to increase the conservation: a step forward is needed to deploy the research toward a deeper comprehension of the whole behaviour of the Basilica to adopt interventions taking in account the gained richness of each object, to improve safety and preservation issues. The research contributed to start delivering modelling protocols contributing guideline and specification to support the LCM across time, to diminish the impact of BIM in term of time and cost effectiveness, and boost preservation in a narrow challenging road.

\section{ACKNOWLEDGEMENTS}

This work was supported by the GAMHer project: Geomatics Data Acquisition and Management for Landscape and Built Heritage in an European Perspective, PRIN, Progetti di Ricerca di Rilevante Interesse Nazionale - Bando 2015, Prot. 2015HJLS7E. The authors would like to thank P. Strada
(Eniservizi), A.Garofalo (Soprintendenza ai Beni Architettonici e Paesaggistici per l'Abruzzo); Proff. A. Franchi, P.Crespi for the images taken during the restoration and BIM-FEA, and M. Trani for the COSIM ones.

\section{REFERENCES}

Banfi F., 2016. Building Information Modelling. A Novel Parametric Modeling Approach Based on 3D Surveys of Historic Architecture. In: Digital Heritage. Progress in Cultural Heritage: Documentation, Preservation, and Protection, 6th International Conference, EuroMed 2016, Springer, pp. 116-127

Barazzetti, L., Banfi, F., Brumana R., Gusmeroli, G., Previtali, M., Schiantarelli, G., 2015b. Cloud-to-BIM-to-FEM: Structural simulation with accurate historic BIM from laser scans. In: Simulation Modeling Practice and Theory, vol. 57, pp. 71-87.

Barazzetti, L., Banfi, F., Brumana, R., Previtali, M., 2015a. Creation of Parametric BIM Objects from Point Clouds Using. In: The Photogrammetric Record, 30(152), p. 339-362.

Barazzetti L., Banfi F., Brumana R., 2016. HBIM in the Cloud. In: Digital Heritage. Progress in Cultural Heritage: Documentation, Preservation, and Protection, EuroMed 2016, Springer, pp. 104-115. "Werner Weber Award".

Crespi, P. G., Franchi, A., Giordano, N., Scamardo, M. A., Ronca, P., 2016. Structural analysis of stone masonry columns of the Basilica S. Maria di Collemaggio. In: Engineering structures, 129, pp.81-90.

Della Torre, S., 2015. Shaping tools for Built Heritage Conservation: from architectural design to program and management. Learning from Distretti culturali. Van Balen, K., et al., Community Involvement in Heritage (Reflections on Cultural Heritage Theories and Practices) pp. 93-102.

Oreni, D., Brumana, R., Della Torre, S., Banfi, F., Barazzetti, L., Previtali, M., 2014. Survey turned into HBIM: the restoration and the work involved concerning the Basilica di Collemaggio after the earthquake (L'Aquila). In: ISPRS Annals of the Photogrammetry, Remote Sensing and Spatial Information Sciences, II/5, pp. 267- 273.

Fai, S. \& Sydor, M., 2013. Building Information Modeling and the Documentation of Architectural Heritage: Between the 'Typical' and the 'Specific. In: Digital Heritage International Congress (DigitalHeritage). Marseilles, France, pp.731-734.

Fai, S., Rafeiro, J., 2014. Establishing an appropriate level of detail (LoD) for a building information model (BIM) -West Block, Parliament Hill, Ottawa, Canada. In: ISPRS Annals of the Photogrammetry, Remote Sensing and Spatial Information Sciences, 2(5), pp.123-130.

Piegl, L. A., Tiller, W., 1997. The NURBS book. Springer

Volk, R., Stengel, J., Schultmann, F., 2014. Building Information Modeling (BIM) for existing buildings - Literature review and future needs. In: Automation in Construction, 38, pp 109-127.

L. 22/01/2004, n. 42. Codice dei beni culturali e del paesaggio;

G.U. 29/01/2008, n. 24 (and 2011 updates). Direttiva per la valutazione e la riduzione del rischio sismico del patrimonio culturale con riferimento alle norme tecniche per le costruzioni.

AEC (CAN) BIM Protocol, 2014. Implementing Canadian BIM Standards for the Architectural, Engineering and Construction industry based on international collaboration.

AIA, 2015, BIM forum, LOD Specification. 